\title{
Antitumor activity of a novel recombinant mutant human tumor necrosis factor-related apoptosis-inducing ligand ${ }^{1}$
}

\author{
Fang FANG $^{2}$, Ai-ping WANG ${ }^{2}$, Shi-fang YANG ${ }^{3}$ \\ ${ }^{2}$ Institute of Materia Medica, Chinese Academy of Medical Sciences and Peking Union Medical College, Beijing 100050; ${ }^{3}$ Beijing Sunbio \\ Biotech LTD, Beijing 100081, China
}

\section{Key words}

antineoplastic agents; tumor necrosis factorrelated apoptosis-inducing ligand; apoptosis; flow cytometry; NCI-H460 cells

\footnotetext{
${ }^{1}$ Project supported by the Innovation Fund for Small Technology-based Firms (No 04C26211100286) and High Technology Research and Development Program of China (863 Program) (No 2005AA2Z3H50) ${ }^{3}$ Correspondence to Prof Shi-fang YANG. Phn 86-10-6891-8579.

Fax 86-10-6891-8595.

Emailysf2k@263.net
}

Received 2005-04-19

Accepted 2005-07-23

doi: $10.1111 / \mathrm{j} .1745-7254.2005 .00206 . x$

\begin{abstract}
Aim: To investigate the antitumor activity and safety of a novel recombinant mutant human tumor necrosis factor-related apoptosis-inducing ligand ( $\mathrm{rmh}$ TRAIL). Methods: Antitumor activity of rmh TRAIL was evaluated by using several tumor cell lines by MTT assay in vitro, and by using a mouse xenograft model in vivo. rmh TRAIL-induced apoptosis in tumor cells was detected by cell death enzyme-linked immunosorbent assay (ELISA), TdT-mediated dUTP nickend labeling (TUNEL) assay and flow cytometry. The safety of rmh TRAIL was also evaluated in several normal human cell lines. Results: At the concentration of $0.32-1000 \mathrm{ng} / \mathrm{mL}$, rmh TRAIL remarkably inhibited the proliferation of 5 tumor cell lines from lung, colon, and breast cancer compared with wild type (wt TRAIL) in vitro, whereas at the concentration of $1 \mathrm{ng} / \mathrm{mL}-10 \mu \mathrm{g} / \mathrm{mL}$, rmh TRAIL showed no or mild cytotoxicity in the normal cell lines. rmh TRAIL $(3,15 \mathrm{mg} / \mathrm{kg}$, ip, once daily for $10 \mathrm{~d}$ ) exerted a significant inhibition on the growth of xenograft tumor NCI-H460 in nude mice compared with the saline group $(P<0.01)$, and was more potent than wt TRAIL, a positive control. The apoptosis of NCI-H460 cells was markedly induced in a concentration-dependent and time-dependent manner after rmh TRAIL treatment. The percentage of apoptotic cells induced by rmh TRAIL in NCI-H460 cells was significantly higher than that by wt TRAIL. Conclusion: rmh TRAIL provided potent antitumor activity in vivo and in vitro, whereas most normal human cells were resisitant to rmh TRAIL. The results suggested that rmh TRAIL might be a useful anticancer agent in future.
\end{abstract}

\section{Introduction}

Apoptosis, or programmed cell death, is a regulated process that is essential to metazoan development and tissue homeostasis $^{[1]}$. Instructive apoptosis plays a physiological role in deletion of activated lymphocytes at the end of an immune response and in elimination of virus-infected cells and oncogenically transformed cells. Deregulation of programmed cell death leads to several human diseases, including cancer, neurodegenerative disorders, and acquired immunodeficiency syndrome ${ }^{[2]}$. Since the 1980s, biotherapy has become an important modality for treating cancer ${ }^{[3]}$. Biotherapy is achieved by inducing apoptosis of tumor cells, which is the ultimate objective of tumor therapy. The mem- bers of the tumor necrosis factor (TNF) family became the focus of biotherapy of cancer ${ }^{[4]}$. Despite the potential of TNF and Fas ligand (FasL; also called CD95L) to induce apoptosis in many types of tumor cells, severe toxic sideeffects preclude both of these ligand from use in systemic anticancer therapy ${ }^{[5,6]}$. TNF infusion causes a lethal inflammatory response that resembles septic shock mediated by activation of the proinflammatory transcription factor NF-kappaB in vascular endothelial cells and macrophages. Infusion of agonistic anti-Fas antibody causes lethal liver damage as a result of the induction of Fas-dependent apoptosis in hepatocytes. Tumor necrosis factor-related apoptosis-inducing ligand (TRAIL, also called Apo2 ligand) is a newly discovered TNF superfamily member initially cloned 
from human heart and lymphocyte cDNA libraries because of its sequence homology to TNF and FasL ${ }^{[7,8]}$. The TRAIL mRNA is constructively expressed at significant levels in many tissues in humans (eg lung, liver, spleen, kidney, thymus, prostate, ovary, intestine, periphero-lymphoid nodes, heart, placenta, and skeletal muscle). Recent studies have shown that TRAIL could induce apoptosis in numerous transformed cell lines of different lineage, but showed nontoxicity systemically unlike TNF and FasL, ionizing radiation and chemotherapy ${ }^{[9-11]}$. The combination of TRAIL and ionizing radiation or chemotherapy appears to have an enhancing effect on cancer therapy, and consequently reduces the dose and side-effects of chemotherapeutants ${ }^{[12-16]}$. Therefore, TRAIL is considered to be the most promising among antitumor agents at present.

TRAIL is expressed as a type II transmembrane protein, as are other members TNF and FasL ${ }^{[8]}$, and its extracellular region forms a soluble molecule upon cleavage ${ }^{[17]}$. There are several forms of recombinant TRAIL: soluble TRAIL fusion protein (termed LZ-TRAIL) in which the extracellular region of the ligand (amino acids 95-281) is linked to an exogenous, modified leucine zipper that drives trimerization ${ }^{[11]}$; soluble TRAIL containing just the extracellular region (amino acids 114-281); polyhistidine-tagged soluble form (his-TRAIL, amino acids 114-281) $)^{[8,18]}$; glutathione $S$-transferase-TRAIL (GST-TRAIL, amino acids 95-281); and flag epitope-tagged form (amino acids 95-281) ${ }^{[8,18]}$. However, these other forms have deficiencies in solubility, antitumor activity and security. Therefore, Beijing Sunbio Biotech developed recombinant mutant human TRAIL (rmh TRAIL). The aim of the present work was to evaluate the antitumor activity of rmh TRAIL in vitro and in vivo, and to explore its antitumor mechanism.

\section{Materials and methods}

Expression and purification of protein Escherichia coli BL21 (DE3) strain was used for the expression of rmh TRAIL. After transformed the plasmid of rmh TRAIL [with a circular permuted extracellular sequence of native human Apo2L/ TRAIL (amino acid 121-281)], which was built by Beijing Sunbio Biotech, into the expression vector, expression was induced by isopropyl-beta- $D$-thiogalactopyranoside (IPTG) at $37^{\circ} \mathrm{C}$ for $4 \mathrm{~h}$. Optimized IPTG concentration was $1 \mathrm{mmol} / \mathrm{L}$ for the protein. Bacteria were harvested and resuspended in phosphate-buffered saline (PBS, containing $137 \mathrm{mmol} / \mathrm{L} \mathrm{NaCl}$, $2.7 \mathrm{mmol} / \mathrm{L} \mathrm{KCl}, 4.3 \mathrm{mmol} / \mathrm{L} \mathrm{Na}_{2} \mathrm{HPO}_{4}, 1.4 \mathrm{mmol} / \mathrm{L} \mathrm{KH}_{2} \mathrm{PO}_{4}$, $\mathrm{pH}$ 7.3), sonicated on an ice bath, and centrifuged before further analysis. Purification of rmh TRAIL was performed with $\mathrm{Ni}^{2+}$-loaded chelating (Amersham Pharmacia Biotech,
Piscataway, USA) and purified protein was subjected to desalting with S-200 (Amersham Pharmacia Biotech). rmh TRAIL molecular weight is $19 \mathrm{kDa}$, and purity is $>98 \%$.

Reagents The wild type TRAIL (wt TRAIL) (amino acids 114-281) used in our experiments was produced by Beijing Sunbio Biotech, or purchased from Merck (Whitehouse Station, USA) (used only in vitro). An Annexin V-FITC apoptosis detection kit was obtained from Oncogene (Cambridge, USA). In situ cell death detection kit (peroxidase, POD) and cell death detection enzyme-linked immunosorbent assay (ELISA) ${ }^{\text {PLUS }}$ kit were from Roche (Nutley, USA). DAB kit was purchased from Beijing Zhongshan Golden Bridge Biotech. MTT was from Sigma (St Louis, USA). DTT and proteinase $\mathrm{K}$ was from Merck. All the reagents, including dimethyl sulfoxide $\left(\mathrm{Me}_{2} \mathrm{SO}\right)$ (Tianjin Fuchen Chemicals Reagent Factory), ethanol, methanol, saturated phenol, paraformaldehyde (Beijing Chemical Reagents Company) were of analytical grade.

Animals BALB/c nude mice (female), 6-8 weeks old, weighing 23-27 g, were supplied by National Institute for the control of Pharmaceutical and Biological Products. Animals were kept at room temperature of $18-22{ }^{\circ} \mathrm{C}$, with a relative humidity of $70 \%$.

Cell culture Tumor cell lines: NCI-H460 human nonsmall cell lung cancer cells and COLO205 human colon cancer cells were obtained from American Type Culture Collection (ATCC); QG-56 human lung squamous cells were obtained from the cell bank of the Chinese Academy of Sciences; MDA-MB-231 and MCF-7 human breast cancer cells were obtained from the Institute of Materia Medica, Chinese Academy of Medical Sciences and Peking Union Medical College.

Normal cell lines: EC-304 human blood vessel endothelial cells were purchased from Nanjing KeyGen Biotech. Human embryonic lung fibroblasts (HELF) were obtained from the Institute of Materia Medica, Chinese Academy of Medical Sciences and Peking Union Medical College. HL7702 normal human hepatocytes were obtained from the cell bank of the Chinese Academy of Sciences. CCC-HEH-1 human primary embryo myocardium-derived cells, CCC-HEL-1 human primary embryo liver-derived cells, CCC-HBE-2 human primary embryo trachea-derived cells, MRC-5 human embryonic lung fibroblasts, CCC-ESF-1 human primary embryo skin fibroblast cells, and HK-2 human primary nephritic tubular epithelium cells, were all obtained from cell center of the Chinese Academy of Medical Sciences and Peking Union Medical College.

NCI-H460, COLO205, QG-56, EC-304, HELFandHL-7702 were cultured in RPMI-1640 medium (GIBCO, Carlsbad, USA) supplemented with $10 \%$ fetal bovine serum (FBS) (Lanzhou 
National HyClone Bio-engineering, Lanzhou, China). MCF-7 and MRC-5 were cultured in Minimum Essential Medium (MEM, GIBCO) supplemented with 10\% FBS. MDA-MB231 cells were cultured in Leibovitz's L-15 medium (GIBCO) supplemented with 15\% FBS. CCC-HEH-1, CCC-HEL-1, CCCHBE-2, and CCC-ESF-1 were cultured in Dulbecco's Modified Eagle's Medium (DMEM) medium (GIBCO) supplemented with $20 \% \mathrm{FBS}$. Insulin $0.2 \mathrm{IU} / \mathrm{mL}$ and hydrocortisone $1 \mu \mathrm{g} / \mathrm{mL}$ were added to CCC-HBE-2 cells. HK-2 cells were cultured in DF-12 medium (GIBCO) supplemented with $10 \%$ FBS.

Cell growth inhibition assay The cytotoxicity of the rmh TRAIL and wt TRAIL was determined using a colorimetric MTT assay. Cells in the logarithmic growth phase were dispersed to prepare a suspension of cell density of $6 \times 10^{4}-20 \times 10^{4} \mathrm{~mL}^{-1}$. Then cell suspension was seeded in a 96-well plate in total volume of $100 \mu \mathrm{L}$ per well and incubated in a $5 \% \mathrm{CO}_{2}$ atmosphere at $37^{\circ} \mathrm{C}$ for $24 \mathrm{~h}$. Then, the supernatant was removed and the cells were added with $100 \mu \mathrm{L}$ of different concentrations of the drugs followed by incubation at $37^{\circ} \mathrm{C}$ for another 24 or $72 \mathrm{~h}$. For controls, cells were placed in medium only. After removal of the supernatant, the cells were treated with $5.0 \mathrm{~g} / \mathrm{L} \mathrm{MTT}$ for $4 \mathrm{~h}$, the purple blue sediment was dissolved in $150 \mu \mathrm{L} \mathrm{Me} 2 \mathrm{SO}$, and the absorbance at $490 \mathrm{~nm}$ was measured using a microplate reader (BIO-RAD, Hercules, USA, model 550). The survival rate of cell growth was calculated using the following formula:

Survival rate $(\%)=A_{490}(\mathrm{drug}) / A_{490}($ control $) \times 100 \%$. Triplicate wells were analyzed for each concentration.

The $50 \%$ inhibitory concentration $\left(\mathrm{IC}_{50}\right)$ is the concentration required for $50 \%$ inhibition, which is calculated from the linear equation, which was educed by concentration versus survival rate regression curve. The experiments were performed in triplicates.

Mouse xenograft tumor model According to the protocol of transplantation tumor research ${ }^{[19]}$, NCI-H460 tumor tissues were chopped into $2 \mathrm{~mm}^{3}$, and then transplanted sc into the right flank of nude mice. The diameter of transplantion tumor was measured with a vernier caliper. When the tumor size grew to $280 \mathrm{~mm}^{3}$, the 32 tumor-grafted mice were randomly divided into 4 groups $(n=8)$; that is, negative control group (treated with normal saline), positive control group (wt TRAIL, $15 \mathrm{mg} / \mathrm{kg}$ ) and rmh TRAIL treated groups (3 and $15 \mathrm{mg} / \mathrm{kg}$ ). All drugs or saline were injected ip once daily for $10 \mathrm{~d}$ followed by another $14 \mathrm{~d}$ observation.

The tumor volume (TV) was calculated using the following formula:

$\mathrm{TV}=1 / 2 \times \mathrm{a} \times \mathrm{b}^{2}$ (in which $\mathrm{a}$ is the length and $\mathrm{b}$ is the width of tumor).
The evaluation index of anti-tumor activity was relative tumor weight inhibition ratio (\%), which was calculated by the following formula:

Tumor weight inhibition ratio $(\%)=(1-\mathrm{T} / \mathrm{C}) \times 100 \%$ (T: test group's or positive control group's mean tumor weight; $\mathrm{C}$ : negative control group's mean tumor weight).

The data were then subjected to a statistical analysis ( $t$-test) for actual efficiency of the material tested.

Assessment of apoptosis Various methods, described below, were used to evaluate NCI-H460 apoptosis.

(a) DNA fragmentation detection by ELISA Acell death detection ELISA kit was used according to the manufacturer's instructions for DNA fragment detection ${ }^{[20]}$. The DNA fragments are discrete multiples of a 180-200 bp subunit, which can be detected as a DNA ladder on agarose gel. The enrichment of mono- and oligonucleosomes in the cytoplasm of the apoptotic cells is a result of DNA degradation that occurs several hours before plasma membrane breakdown. The principle on which this test is based is the detection of mono- and oligonucleosomes in the cytoplasmic fractions of cell lysates by using biotinylated antihistoneand peroxidase-coupled anti-DNA antibodies. The enrichment of mono- and oligonucleosomes released into the cytoplasm is calculated as the ratio of absorbance of sample cells to absorbance of control cells. The enrichment factor was used as a parameter of apoptosis and is shown on the $\mathrm{Y}$ axis as mean $\pm \mathrm{SD}$ of triplicate experiments performed in triplicates. An enrichment factor of 1 represents spontaneous apoptosis. NCI-H460 were grown in 96-well plates and exposed to rmhTRAIL $10 \mathrm{ng} / \mathrm{mL}$ for 0.5 to $4 \mathrm{~h}$ or 0.0128 $\mathrm{ng} / \mathrm{mL}$ to $40 \mathrm{ng} / \mathrm{mL}$ for $2 \mathrm{~h}$.

(b) TdT-mediated dUTP nick-end labeling (TUNEL) assay After incubated with $15 \mathrm{ng} / \mathrm{mL}$ rmh TRAIL for 1, 2, and $4 \mathrm{~h}$, NCI-H460 cells were smeared on slides, fixed by $4 \%$ paraformaldehyde in PBS ( $\mathrm{pH}$ 7.2) for $30 \mathrm{~min}$ at room temperature, washed 3 times with PBS, and blocked by $0.3 \%$ $\mathrm{H}_{2} \mathrm{O}_{2}$. Then, cells were permeabilized on ice using $0.3 \%$ Triton X-100 in PBS for $2 \mathrm{~min}$. Subsequent operations were refered to the manufacturer's instruction of In situ cell death detection kit and DAB kit. The samples were dehydrated by ethanol and cleared in dimethylbenzene, analyzed by microscopy and photos were taken using a Nikon 4500 digital camera.

(c) Flow cytometry For apoptotic cell detection analysis, NCI-H460 cells were treated with rmh TRAIL or wt TRAIL (1, 10 , and $100 \mathrm{ng} / \mathrm{mL}$ ) for $12 \mathrm{~h}$. All of the attached and the detached cells were harvested. Detection of the apoptotic cells was referred to the manufacturer's instruction of Annexin V-FITC apoptosis detection kit. 
Results evaluation:

Non-apoptotic cells: Annexin V negative and PI negative; Early apoptotic cells: Annexin V positive and PI negative;

Necrotic cells or late apoptotic cells: Annexin V positive and PI positive.

Statistical analysis Data were expressed as mean \pm SD. Data of the representatives were analyzed for statistical significance using a $t$-test. $P<0.05$ was considered statistically significant.

\section{Results}

Various tumor cell lines are sensitive to rmh TRAILinduced death in vitro To explore the antitumor activity of rmh TRAIL against a spectrum of cancer cell lines, we tested its effect in vitro on the inhibition of 5 different cell lines derived from cancers of the lung, colon, and breast ( 2 lung cancer cell lines, 2 breast cancer cell lines, and 1 colon cancer cell line) by MTT assay. rmh TRAIL exerted a cytotoxic effect on these cell lines and inhibited cell growth after cells being treated for $24 \mathrm{~h}$ or $72 \mathrm{~h}$. Furthermore, the antitumor activity of rmh TRAIL was notably higher than that of wt TRAIL, and $\mathrm{IC}_{50}$ for rmh TRAIL against all cell lines were significantly lower than wt TRAIL (Table $1, P<0.01$ ). Treatment with $\mathrm{rmh}$ TRAIL at the dose of $200 \mathrm{ng} / \mathrm{mL}$ caused substantial cell death. The morphology of the cells treated by rmh TRAIL was characteristic of apoptotic cells: blebbing and shrinkage of cytoplasm (Figure 1).

\section{Antitumor activity of rmh TRAIL in a mouse xenograft} study To determine whether the tumoricidal activity of rmh TRAIL observed in vitro could be demonstrated in vivo, $\mathrm{BALB} / \mathrm{c}$ nude mice were transplanted sc with NCI-H460 tumor tissue, which showed intermediate sensitivity to rmh TRAIL in vitro (Table 1), and allowed tumors to establish. The tumors in the control group grew steadily in an exponential manner. wt TRAIL treatment gave a $25.7 \%$ reduction in mean tumor volume, which was lower than that of rmh TRAIL. In contrast, the rmh TRAIL treated groups showed a marked reduction in tumor size, especially during the treatment period (Figure 2, Table 2). The tumors in some

Table 1. Antitumor activity of rmh TRAIL and wt TRAIL on human tumor cell lines in vitro represented by $\mathrm{IC}_{50} . n=3$. Mean $\pm \mathrm{SD}$. ${ }^{\mathrm{c}} P<0.01$ vs wt TRAIL.

\begin{tabular}{lll}
\hline Tumor cell lines & \multicolumn{2}{c}{$\mathrm{IC}_{50} / \mu \mathrm{g} \cdot \mathrm{mL}^{-1}$} \\
& rmh TRAIL & wt TRAIL \\
\hline COLO205 & $0.007 \pm 0.003^{\mathrm{c}}$ & $0.260 \pm 0.051$ \\
MDA-MB-231 & $0.006 \pm 0.004^{\mathrm{c}}$ & $0.121 \pm 0.038$ \\
NCI-H460 & $0.006 \pm 0.003^{\mathrm{c}}$ & $0.238 \pm 0.052$ \\
QG-56 & $0.012 \pm 0.003^{\mathrm{c}}$ & $0.804 \pm 0.082$ \\
MCF-7 & $0.086 \pm 0.038^{\mathrm{c}}$ & $>1 \mu \mathrm{g} / \mathrm{mL}$ \\
\hline
\end{tabular}

rmh TRAIL, recombinant mutant human TRAIL; wt TRAIL, wild type TRAIL.
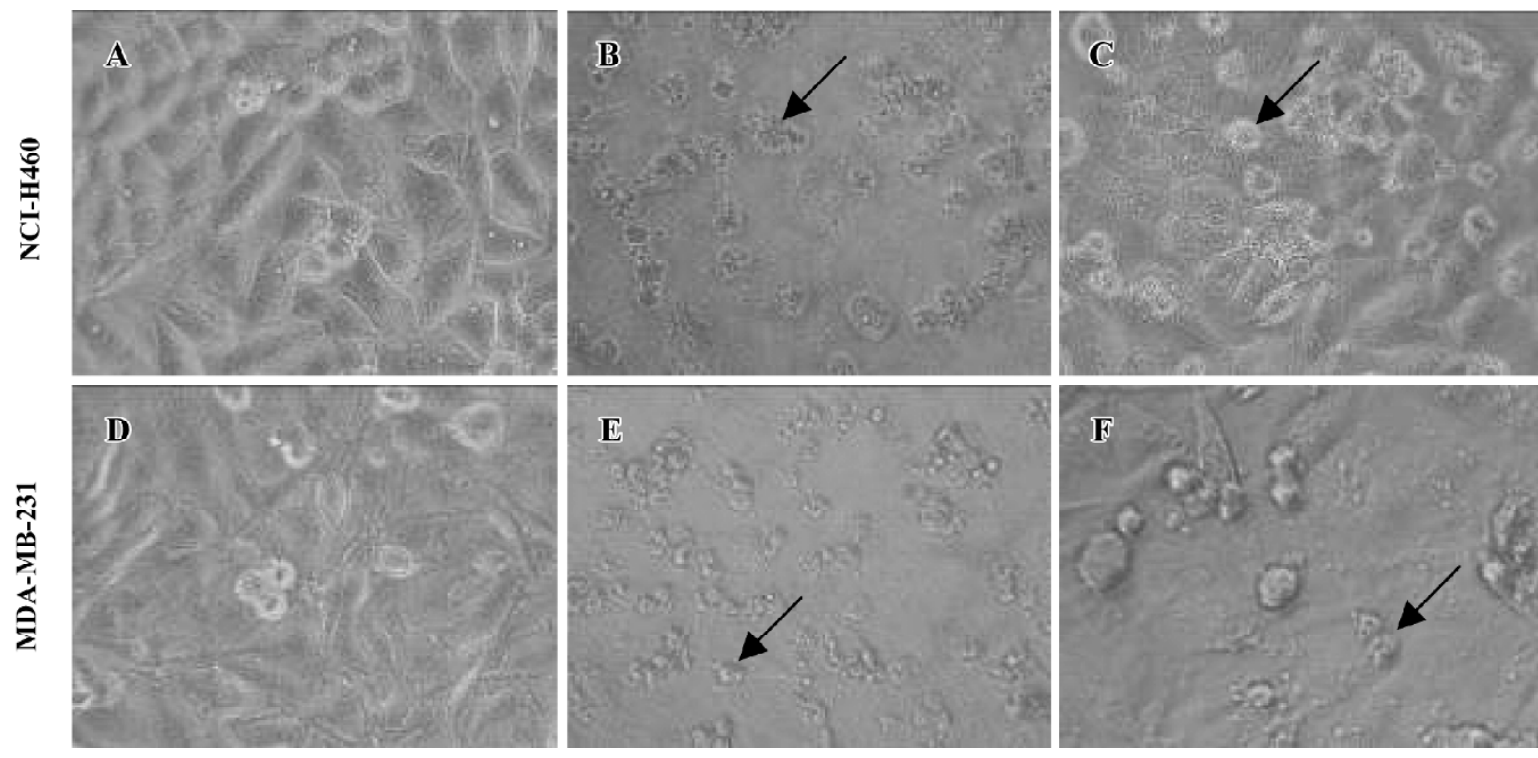

Figure 1. Morphological changes of NCI-H460 cells (A-C) and MDA-MB-231 cells (D-F), A and D: control, untreated. B and E: treated with recombinant mutant human (rmh) TRAIL $200 \mathrm{ng} / \mathrm{mL}$ for $24 \mathrm{~h}$. C and F: treated with wild type (wt) TRAIL $200 \mathrm{ng} / \mathrm{mL}$ for $24 \mathrm{~h}$. The photographs were taken using an Olympus CK40 inverted laboratory system microscope $(\times 20)$. Arrow indicates dead cells. 
Table 2. The experimental therapeutic efficacy of ip injection of rmh TRAIL and wt TRAIL on xenograft tumor NCI-H460 in nude mice. $n=8$. Mean \pm SD. ${ }^{\mathrm{c}} P<0.01$ vs control. ${ }^{\mathrm{f}} P<0.01$ vs $\mathrm{rmh}$ TRAIL $15 \mathrm{mg} / \mathrm{kg} .{ }^{\mathrm{i}} P<0.01$ vs $\mathrm{rmh}$ TRAIL $3 \mathrm{mg} / \mathrm{kg}$.

\begin{tabular}{|c|c|c|c|c|c|c|c|}
\hline \multirow[t]{2}{*}{ Group } & \multirow[t]{2}{*}{ Dose $/ \mathrm{mg} \cdot \mathrm{kg}^{-1}$} & \multicolumn{2}{|c|}{ Animal number } & \multicolumn{2}{|c|}{ Body weight/g } & \multirow[t]{2}{*}{ Tumor weight/g } & \multirow{2}{*}{$\begin{array}{c}\text { Inhibition } \\
\text { ratio/\% }\end{array}$} \\
\hline & & $\mathrm{D}_{0}$ & $\mathrm{D}_{n}$ & $\mathrm{D}_{0}$ & $\mathrm{D}_{n}$ & & \\
\hline Control & 0 & 8 & 8 & $24.1 \pm 1.4$ & $29.4 \pm 1.9$ & $3.15 \pm 0.50$ & \\
\hline rmh TRAIL & 15 & 8 & 8 & $26.2 \pm 1.0$ & $27.1 \pm 1.7$ & $0.42 \pm 0.18^{c}$ & 86.7 \\
\hline rmh TRAIL & 3 & 8 & 8 & $24.5 \pm 1.6$ & $27.4 \pm 1.0$ & $1.12 \pm 0.36^{\mathrm{cf}}$ & 64.4 \\
\hline wt TRAIL & 15 & 8 & 8 & $24.6 \pm 1.4$ & $29.3 \pm 1.3$ & $2.34 \pm 0.42^{\mathrm{ci}}$ & 25.7 \\
\hline
\end{tabular}

$\mathrm{D}_{0}$, the day of the start of treatment; $\mathrm{D}_{n}$, the day of the end of the experiments, which was after a 10 day treatment and a 14 day withdrawal. rmh TRAIL, recombinant mutant human TRAIL; wt TRAIL, wild type TRAIL.

mice in the high-dose rmh TRAIL group became invisible during the treatment period and shortly after withdrawal. The suppressed tumors recommenced growing $5 \mathrm{~d}$ after withdrawal, but still more slowly than the control group. The inhibitory effect of rmh TRAIL on transplantation of tumor NCI-H460 was in a dose-dependent manner. Tumor suppression in $3 \mathrm{mg} / \mathrm{kg}$ rmh TRAIL-treated group was less than $15 \mathrm{mg} / \mathrm{kg}$ group, but greater than $15 \mathrm{mg} / \mathrm{kg}$ in the wt TRAILtreated group (Figure 2, Table 2).

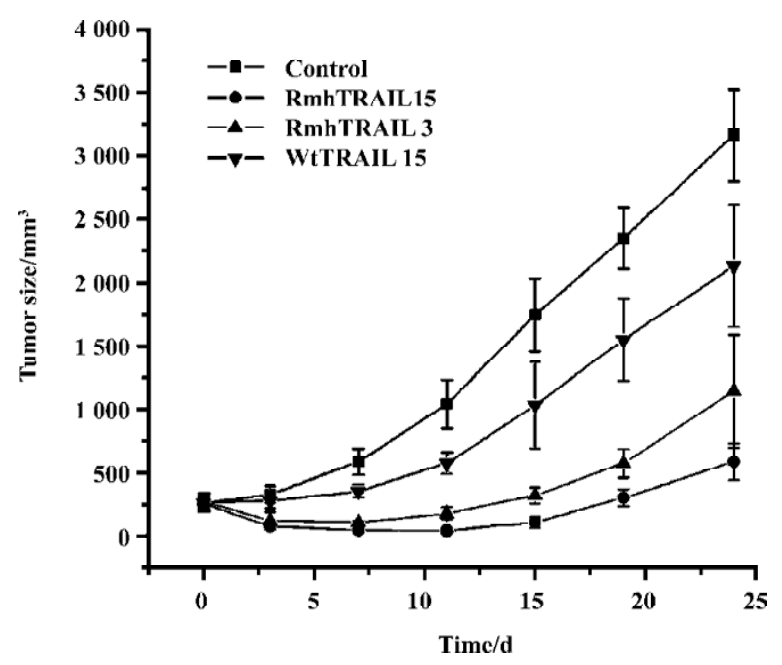

Figure 2. Inhibitory effects of rmh TRAIL and wt TRAIL on the volumes of xenograft tumor NCI-H460 in nude mice. $n=8$. Mean \pm SD. Control: normal saline group; recombinant mutant human (rmh) TRAIL-15: $15 \mathrm{mg} / \mathrm{kg}$ rmh TRAIL-treated group; rmh TRAIL-3: 3 $\mathrm{mg} / \mathrm{kg}$ rmh TRAIL-treated group; wild type (wt) TRAIL-15: 15 $\mathrm{mg} / \mathrm{kg}$ wt TRAIL-treated group. All drugs or saline was injected ip once daily for $10 \mathrm{~d}$ followed by $14-\mathrm{d}$ observation.

Apoptosis induced by rmh TRAIL a.rmh TRAIL-induced cell death of $\mathrm{NCl}-\mathrm{H} 460$ cells detected by ELISA rmh TRAIL $10 \mathrm{ng} / \mathrm{mL}$ was chosen for DNA fragmentation experiment by ELISA at different time points. This concentration of rmh TRAIL-induced apoptosis showed a time-dependent manner. At 2 and $4 \mathrm{~h}$ after treatment, rmh TRAIL induced a significant increase of cytoplasmic nucleosomes (Figure 3A). The result accords with agarose gel electrophoesis result (data not shown). More-over, we examined different concentrations (from $0.0128 \mathrm{ng} / \mathrm{mL}$ to $40 \mathrm{ng} / \mathrm{mL}$ ) of rmh TRAIL-induced apoptosis for $2 \mathrm{~h}$. The result showed a dose-dependent manner (Figure 3B).

b. TUNEL assay The pictures displayed in the Figure 4 were taken after incubation with rmh TRAIL $15 \mathrm{ng} / \mathrm{mL}$ for 1 , 2 , and $4 \mathrm{~h}$. The nucleus condensation and segmentation were observed by microscope. Lots of apoptotic bodies were found in rmh TRAIL-treated cells but none in untreated cells.

c. Flow cytometry To confirm that the percentage of apoptosis induced by various concentration of rmh TRAIL in NCI-H460 cells, Annexin V and PI double staining and flow cytometry were performed. The percentages of apoptosis induced by rmh TRAIL and wt TRAIL (1 ng/mL, $10 \mathrm{ng} / \mathrm{mL}$, $100 \mathrm{ng} / \mathrm{mL}$ ) for $12 \mathrm{~h}$ were $8.11 \%, 32.80 \%, 59.68 \%$ and $4.96 \%$, 7.08\%, 14.11\%, respectively (Figure 5).

Effect of rmh TRAIL on normal cell types To test whether rmh TRAIL initiates apoptosis in normal cells, 9 lines of normal cells, were exposed to rmh TRAIL $(1 \mathrm{ng} / \mathrm{mL}-10 \mu \mathrm{g} / \mathrm{mL})$ or wt TRAIL ( $1 \mathrm{ng} / \mathrm{mL}-10 \mu \mathrm{g} / \mathrm{mL}$ ) for $24 \mathrm{~h}$. No morphological evidence of apoptosis was observed as induced by rmh TRAIL (except for HL-7702); in addition, there was no decreased cell viability in staining of the cells by MTT (Figure 6), which indicated that rmh TRAIL was not cytotoxic toward these normal cell types. There was mild injury on HL7702 hepatocytes elicited by both rmh TRAIL and wt TRAIL, and no cytotoxicity on CCC-HEL-1, human primary embryo liver-derived cells (Figure 6). The $\mathrm{IC}_{50}$ of rmh TRAIL and wt 

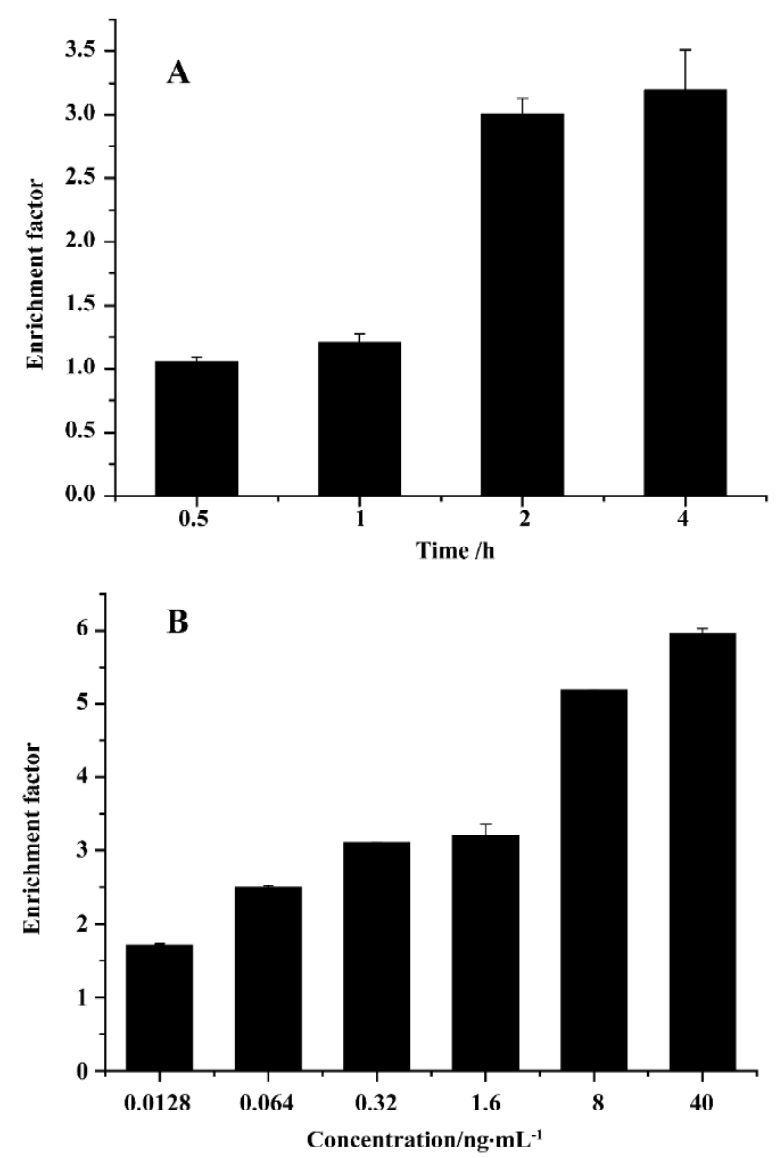

Figure 3. Quantification of nucleosomal DNA fragmentation. The cell death detection ELISA ${ }^{\text {PLUS }}$ was used to quantify DNA fragmentation in NCI-H460 cells undergoing apoptosis in the presence of recombinant mutant human (rmh) TRAIL; A) rmh TRAIL $10 \mathrm{ng} / \mathrm{mL}$ treated for different time $(0.5,1,2$ and $4 \mathrm{~h})$; B) treatment with different concentrations of rmh TRAIL $(0.0128 \mathrm{ng} / \mathrm{mL}-40 \mathrm{ng} / \mathrm{mL})$ for $2 \mathrm{~h}$. The rate of apoptosis is reflected by the enrichment factor of nucleosomes in the cytoplasm shown on the $Y$ axis. An enrichment factor of 1 is equivalent to background apoptosis. Experiments were performed in triplicate and repeated 3 times. $n=3$. Mean \pm SD.

TRAIL on HL-7702 exceeded $10 \mu \mathrm{g} / \mathrm{mL}$.

\section{Discussion}

Although TNF and FasL have potent cytotoxic activity against many types of tumor cells, the application of these death ligands to cancer therapy has been restricted by their severe toxicity to normal tissues. The discovery of TRAIL as a death ligand, with its wide tissue-mRNA distribution and its unique receptor system, suggests that this ligand might be more suitable than TNF or FasL for systemic cancer therapy.

rmh TRAIL, developed by Beijing Sunbio Biotech, is a mutant form of human native TRAIL, but the functional sequences are conservative. Native TRAIL is expressed as a type II transmembrane protein that can be cleaved proteolytically to form a soluble homotrimer ${ }^{[7,8]}$. The therapeutic potential of a recombinant soluble version of human TRAIL that can be produced in E coli and purified as a $60-\mathrm{kDa}$ homotrimer has been evaluated ${ }^{[9,11]}$. An optimized antineoplastic agent can selectively induce apoptosis of cancer cells while sparing normal cells. Some scientists have oppugned the safety of TRAIL on hepatocytes ${ }^{[22,23]}$. To obtain a form of TRAIL that has higher antitumor activity and safety, Beijing Sunbio Biotech produced rmh TRAIL with a circular permuted extracellular sequence of native human Apo2L/TRAIL. Our previous work revealed that rmh TRAIL had a high affinity for its death receptors and water-solubility (data not shown). This molecule forms more stable homotrimers. The pharmacokinetics research of rmh TRAIL indicates that the concentration in tumor tissue was higher than that in plasma. Furthermore, rmh TRAIL was more resistant to trypsin proteolysis in vitro than wt TRAIL (data not shown). All of the above suggests that rmh TRAIL could contribute to long-standing antitumor activity.

The present study first assesses the antitumor activity of rmh TRAIL in vitro. A spectrum of cancer cell lines exhibited sensitivity in vitro to rmh TRAIL. This finding is consistent with previous reports that native TRAIL is cytotoxic toward cell lines from cancers of the lung, colon, and breas $^{[9-11]}$. rmh TRAIL triggers more cell death in vitro than wt TRAIL. The study of NCI-H460 xenograft models indicates that rmh TRAIL can cause tumor regression or suppress tumor growth, and can initiate tumor cell apoptosis, which is consistent with its apoptosis-inducing activity in vitro. The antitumor activity of TRAIL after ip administration has been demonstrated in several mouse xenograft models of human cancers, including colorectal ${ }^{[9]}$, breast ${ }^{[1]}$, and glioma $^{[24]}$. rmh TRAIL caused a dose-dependent suppression of tumor growth, and $15 \mathrm{mg} / \mathrm{kg} \mathrm{rmh}$ TRAIL resulted in a $86.7 \%$ reduction in mean tumor volume, whereas wt TRAIL only caused a $25.7 \%$ reduction using the same dose. Therefore, in the present study, the antitumor activity of rmh TRAIL is higher than that of wt TRAIL in the experiments both in vivo and in vitro. Compared with wt TRAL, rmh TRAIL can achieve same antitumor activity under lower dosages.

Second, rmh TRAIL induced apoptosis in NCI-H460 was confirmed by cell death ELISA assay, TUNEL assay, and flow cytometry. Nucleus condensation, apoptotic body appearance, and DNA fragmentation are universal characteristics in the cells undergoing apoptosis. Furthermore, cell 

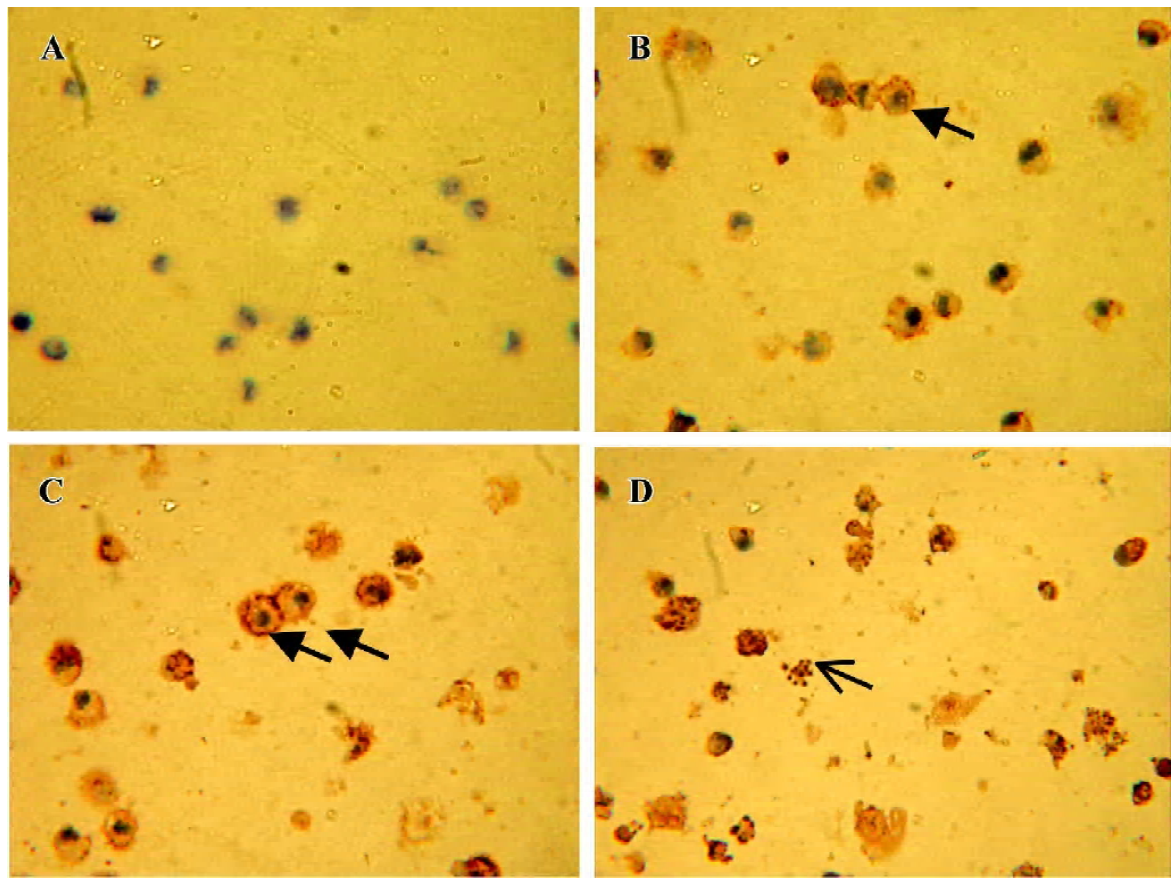

Figure 4. In situ detection of DNA fragmentation by TdT-mediated dUTP nick-end labeling (TUNEL) method: showing condensation and segmentation of nucleus in NCI-H460 cells at different times after treatment with $15 \mathrm{ng} / \mathrm{mL}$ recombinant mutant human (rmh) TRAIL. (A) Control (no TdT); (B) rmh TRAIL 1 h; (C) rmh TRAIL 2 h; (D) rmh TRAIL 4 h; $(\times 20)$.

$\uparrow$ Apoptotic cells: chromatin condensation and present circularity

个 Apoptotic cells: small vesicles called apoptotic bodies

A

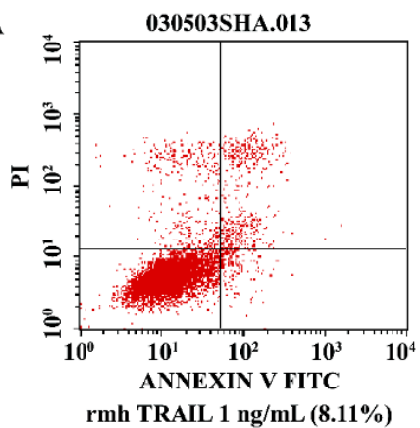

D

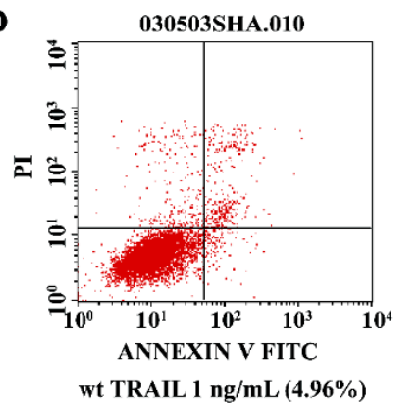

B

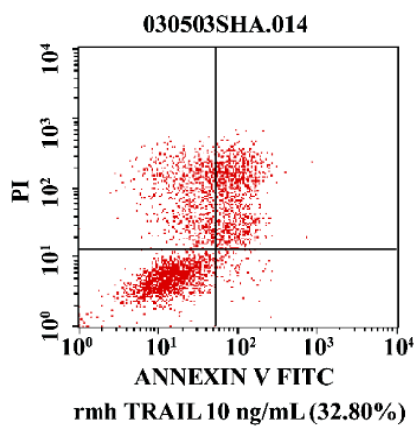

$\mathbf{E}$

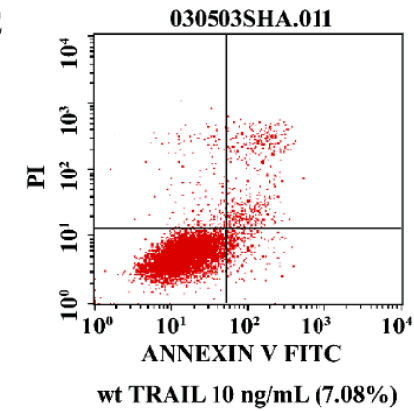

C

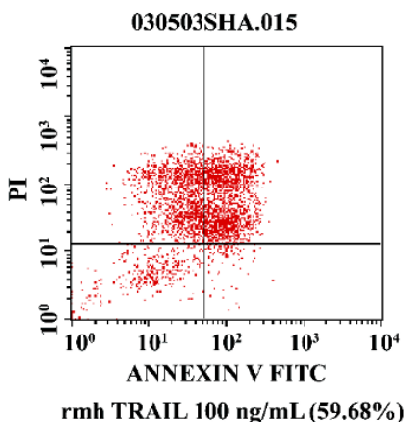

F

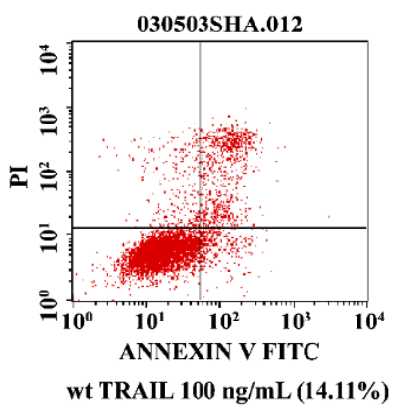

Figure 5. The flow cytometry using Annexin-V/PI double staining was performed on NCI-H460 cells. Representative dot plots of recombinant mutant human (rmh) TRAIL 1, 10, $100 \mathrm{ng} / \mathrm{mL}$ (A-C) and wild type (wt) TRAIL 1, $10,100 \mathrm{ng} / \mathrm{mL}$ (D-F) treated for $12 \mathrm{~h}$. The numbers in brackets denote percentage of apoptotic cells. The upper right quadrant represents apoptotic or necrotic cells positive for both Annexin and PI. Data from $1 \times 10^{4}$ cell per sample were collected. 

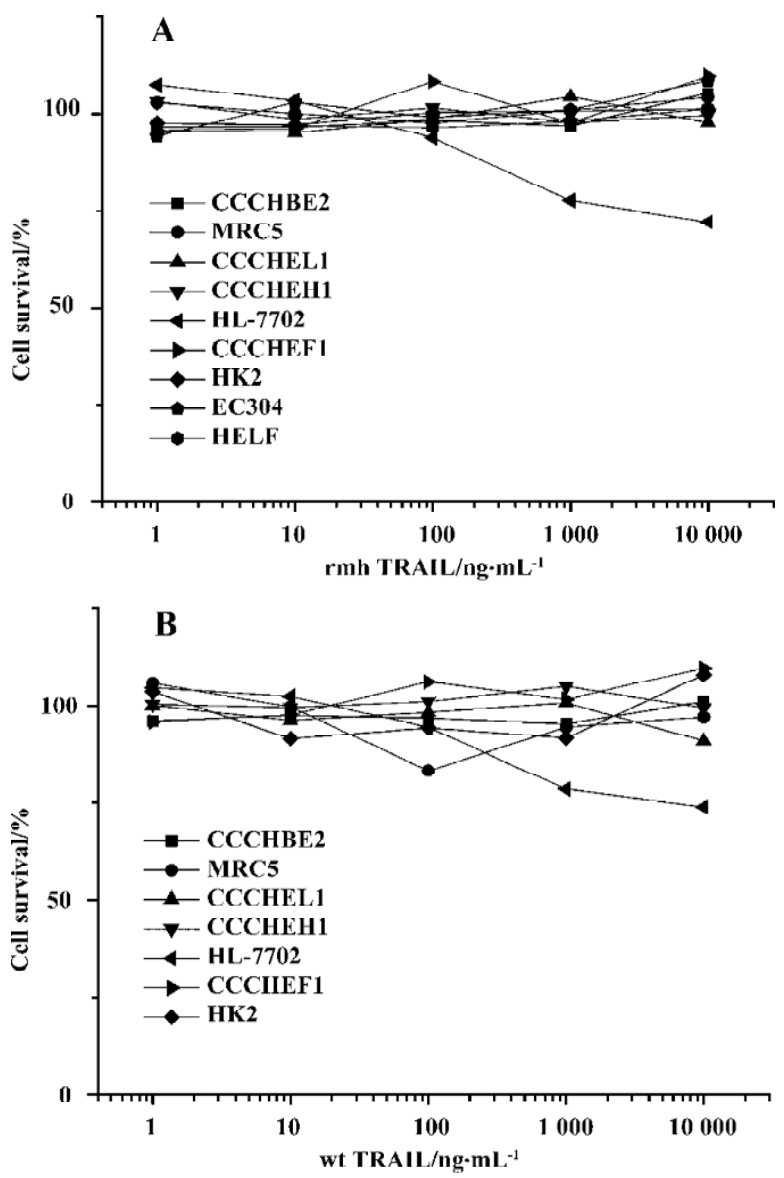

Figure 6. Effect of rmh TRAIL or wt TRAIL on proliferation in normal cell lines. Cells were incubated with serial dilutions of recombinant mutant human $(\mathrm{rmh})$ TRAIL $(1 \mathrm{ng} / \mathrm{mL}-10 \mu \mathrm{g} / \mathrm{mL})$ or wild type (wt) TRAIL ( $1 \mathrm{ng} / \mathrm{mL}-10 \mu \mathrm{g} / \mathrm{mL})$ for $24 \mathrm{~h}$, and cell growth relative to medium controls was determined by MTT assay.

death ELISA assay and flow cytometry showed the quantity of apoptotic cells. From the evidence in the present study, it is elicited that rmh TRAIL could induce NCI-H460 apoptosis, that and it is time- and concentration-dependent.

Third, MTT assay was used to examine the cytotoxicity effect of rmh TRAIL on normal cells. Although rmh TRAIL was cytotoxic toward many tumor cell lines in vitro, rmh TRAIL showed no inhibition on normal cells tested in the experiment from endothelial, fibroblastic, myocardial, cutaneous, lung, renal, and tracheal origin, supporting the notion that rmh TRAIL dose did not increase cytotoxicity to generally nontransformed cells. The results are consistent with Ashkenazi et al $l^{[9,10,25,26]}$. rmh TRAIL and wt TRAIL showed mild cytotoxicity to HL-7702 cells, which are separated from adult liver. The $\mathrm{IC}_{50}$ of rmh TRAIL exceeded 10 $\mu \mathrm{g} / \mathrm{mL}$. The $\mathrm{IC}_{50}$ for non-small cell lung cancer and colonic cancer, the main clinical indications, are all $0.01 \mu \mathrm{g} / \mathrm{mL}$, which is at least 1000 times lower than the $\mathrm{IC}_{50}$ for HL-7702. Furthermore, the pharmacokinetics research on nonhuman primates (cynomolgus monkeys) indicated that the maximal plasma concentration $\left(C_{\max }\right.$ ) of rmh TRAIL (iv, $5 \mathrm{mg} / \mathrm{kg}$ ) was $25 \mu \mathrm{g} / \mathrm{mL}$ (data not shown). The dose used in humans would be no more than $5 \mathrm{mg} / \mathrm{kg}$. Therefore, the $C_{\max }$ will be no more than $25 \mu \mathrm{g} / \mathrm{mL}$, which is less than the $\mathrm{IC}_{50}$ of HL-7702. The results suggest that the clinical effective dose of rmh TRAIL might be safety for human.

In conclusion, rmh TRAIL provided potent antitumor activity in vitro and in vivo, although it did not exert obvious cytotoxicity on a wide variety of normal cells. Therefore, rmh TRAIL might prove to be a useful new agent in fighting cancer cells, leaving normal cells unharmed.

\section{References}

1 Jacobson MD, Weil M, Raff MC. Programmed cell death in animal development. Cell 1997; 88: 347-54.

2 Steller H. Mechanisms and genes of cellular suicide. Science 1995; 267: 1445-9.

3 Wyllie AH. Apoptosis: cell death in tissue regulation. J Pathol 1987; 153: 313-6.

4 Moriya N, Miwa H, Orita K. Antitumor effects of bacterial lipopolysaccharide and tumor necrosis factor in mice. Jpn J Surg 1984; 14: 163-6.

5 Ishida Y, Kondo T, Tsuneyama K, Lu P, Takayasu T, Mukaida N. The pathogenic roles of tumor necrosis factor receptor p55 in acetaminophen-induced liver injury in mice. J Leukoc Biol 2004; 75: 59-67.

6 Lombard C, McKallip RJ, Hylemon PB, Nagarkatti PS, Nagarkatti M. Fas ligand-dependent and -independent mechanisms of toxicity induced by $\mathrm{T}$ cell lymphomas in lymphoid organs and in the liver. Clin Immunol 2003; 109: 144-53.

7 Wiley SR, Schooley K, Smolak PJ, Din WS, Huang CP, Jillian K, et al. Identification and characterization of a new member of the TNF family that induces apoptosis. Immunity 1995; 3 : 673-82.

8 Pitti RM, Marsters SA, Ruppert S, Donahue CJ, Moore A, Ashkenzai A. Induction of apoptosis by Apo-2 ligand, a new member of the tumor necrosis factor cytokine family. J Biol Chem 1996; 271: 12687-90.

9 Ashkenazi A, Pai RC, Fong S, Leung S, Lawrence DA, Marsters SA, et al. Safety and antitumor activity of recombinant soluble Apo2 ligand. J Clin Invest 1999; 104: 155-62.

10 Kelley SK, Harris LA, Xie D, DeForge L, Totpal K, Bussiere J, et al. Preclinical studies to predict the disposition of Apo2L/tumor necrosis factor-related apoptosis-inducing ligand in humans: characterization of in vivo efficacy, pharmacokinetics, and safety. J Pharmacol Exp Ther 2001; 299: 31-8.

11 Walczak H, Miller RE, Ariail K, Gliniak B, Griffith TS, Kubin M, et al. Tumoricidal activity of tumor necrosis factor-related apoptosis-inducing ligand in vivo. Nat Med 1999; 5: 157-63.

12 Voelkel-Johnson C, King DL, Norris JS. Resistance of prostate cancer cells to soluble TNF-related apoptosis-inducing ligand 
(TRAIL/Apo2L) can be overcome by doxorubicin adenoviral delivery of full-length TRAIL. Cancer Gene Ther 2002; 9: 16472.

13 Yoshida S, Narita T, Koshida S, Ohta S, Takeuchi Y. TRAIL/ Apo2L ligands induce apoptosis in malignant rhabdoid tumor cell lines. Pediatr Res 2003; 54: 709-17.

14 Bouralexis S, Findlay DM, Atkins GJ, Labrinidis A, Hay S, Evdokiou A. Progressive resistance of BTK-143 osteosarcoma cells to Apo2L/TRAIL-induced apoptosis is mediated by acquisition of DcR2/TRAIL-R4 expression: resensitisation with chemotherapy. Br J Cancer 2003; 89: 206-14.

15 Frese S, Brunner T, Gugger M, Uduehi A, Schmid RA. Enhancement of Apo2L/TRAIL(tumor necrosis factor-related apoptosisinducing ligand)-induced apoptosis in non-small cell lung cancer cell lines by chemotherapeutic agents without correlation to the expression level of cellular protease caspase- 8 inhibitory protein. J Thorac Cardiovasc Surg 2002; 123: 168-74,

16 Evdokiou A, Bouralexis S, Atkins GJ, Chai F, Hay S, Clayer M, et al. Chemotherapeutic agents sensitize osteogenic sarcoma cells, but not normal human bone cells, to Apo2L/TRAIL-inducing apoptosis. Int J Cancer 2002; 99: 491-504.

17 Mariani SM, Matiba B, Armandola EA, Krammer PH. Interleukin 1 beta-converting enzyme related proteases/caspases are involved in TRAIL-induced apoptosis of myeloma and leukemia cells. J Cell Biol 1997; 137: 221-9.

18 Marsters SA, Pitti RM, Donahue CJ, Ruppert S, Bauer KD, Ashkenazi A, et al. Activation of apoptosis by Apo-2 ligand is independent of FADD but blocked by CrmA. Curr Biol 1996; 6: $750-2$.
19 Wand WR. In vivo methods. In: Teicher BA, editor. Anticancer drug development guide, preclinical screening, clinical trials, and approval. Humana Press: Totowa NJ; 1997. p59-213.

20 Aragane YD, Kulms D, Metza D, Wilkes G, Poppelman B, Luger TA, et al. Ultraviolet light induces apoptosis via direct activation of CD95 (Fas/Apo-1) independently of its ligand CD95L. J Cell Biol 1998; 140: 171-82

21 Hymowitz SG, O’Connell MP, Ultsch MA, Hurst A, Totpal K, Ashkenzai A, et al. A unique zinc-binding site revealed by a highresolution x-ray structure of homotrimeric Apo2L/TRAIL. Biochemistry 2000; 39: 633-40.

22 Armeanu S, Lauer UM, Smirnow I, Schenk M, Weiss TS, Gregor $\mathrm{M}$, et al. Adenoviral gene transfer of tumor necrosis factorrelated apoptosis-inducing ligand overcomes an impaired response of hepatoma cells but causes severe apoptosis in primary human hepatocytes. Cancer Res 2003; 63: 2369-72.

23 Mundt B, Kuhnel F, Zender L, Paul Y, Tillmann H, Trautwein C, et al. Involvement of TRAIL and its receptors in viral hepatitis. FASEB J 2003; 17: 94-6.

24 Roth W, Isenman S, Naumann U, Kugler S, Bahr M, Dichgans JA, et al. Locoregional Apo2L/TRAIL eradicates intracranial human malignant glioma xenografts in athymic mice in the absence of neurotoxicity. Biochem Biophys Res Commun 1999; 265: 479-83.

25 Lawrence D, Shahrokh Z, Marsters S, Achilles K, Shih D, Mounho $\mathrm{B}$, et al. Differential hepatocyte toxicity of recombinant Apo2L/ TRAIL versions. Nat Med 2001; 7: 383-5.

26 Srivastava RK. TRAIL/Apo-2L: mechanisms and clinical applications in cancer. Neoplasia 2001; 3: 535-46. 